\title{
Documentos
}

\section{Colombia y su relación con los demás países de la región en la coyuntura actual}

\author{
Luis Guillermo Giraldo
}

Comienzo con manifestar mi gratitud al Convenio Andrés Bello y en especial a su Secretario Ejecutivo, Don Pedro Henríquez, por su invitación a participar en este foro. Agradezco también la hospitalidad a la Universidad de Chile y al Instituto de Estudios Internacionales.

El tema que me corresponde a mí es el actual proceso colombiano, y cómo se encuadra en el contexto de la comunidad internacional. Para introducirnos en el tema digamos que Colombia ha sido un país que no ha marchado, sobre todo en los últimos tiempos, al compás en que han marchado la mayoría de los demás países latinoamericanos. Como, cuando existió la famosa crisis de la deuda externa en América Latina, Colombia no vivió ese problema. Como, el hecho de la crisis de la democracia en América Latina, cuando florecieron tantas dictaduras en tantos países, Colombia no vivió ese problema, y tuvo su régimen democrático. Por último, cuando el fenómeno guerrille-ro se posicionó en América Latina, en Colombia teníamos guerrillas pero no era un fenómeno de la magnitud ni del desafío con que se presentó en los de-más países de América Latina. Entonces, yo diría que hemos marchado a un ritmo diferente en ciertos hechos, frente al resto de América Latina. Y cuando el resto de los países tiene solucionado el problema guerrillero y el problema subversivo, en Colombia desafortunadamente hemos llegado a lo que podría considerarse el clímax del problema guerrillero, y ese va a ser el tema de mi disertación. 
El problema de las guerrillas en América Latina se introducía en el contexto internacional cuando estábamos dentro del tema de la Guerra Fría. Caído el muro de Berlín, fracasado el marxismo como sistema de organización política, comienzan a derrumbarse también las guerrillas en América Latina pero no ocurre así en Colombia. Colombia, después de la caída del muro de Berlín, mantiene una guerrilla que tiene una dinámica propia, que se ve en el contexto intemacional como un problema eminentemente doméstico. Hasta hace muy poco tiempo, el Embajador de Estados Unidos en Colombia sostenía que la guerrilla era un asunto interno de Colombia, que había una relación con el narcotráfico, pero que la guerrilla no podía ser considerada en Colombia como un Cartel. Mas, sin embargo, se van presentando una serie de circunstancias que le permiten al estado colombiano afirmar, que les permiten a los Estados Unidos sostener, y que le permiten a la comunidad internacional saber que había una alianza entre la guerrilla colombiana y el narcotráfico, y que desaparecidas las fuentes de financiamiento internacionales para la guerrilla colombiana, ésta toma sus ingresos de dos fuentes principales: el narcotráfico y los secuestros.

La guerrilla colombiana, entonces, en un pleno que se inició en el año 1983, tomó la decisión, me refiero al congreso de las Fuerzas Armadas Revolucionarias de Colombia(FARC), de hacer una alianza financiera con el narcotráfico. Proteger al narcotráfico y cobrarle un gramaje, un peaje, una contribución por esa protección. Desde ese mismo año la guerrilla colombiana comienza a crecer financieramente, en organización, en poderío, en armamento, en infiltración, en muchos sectores de la sociedad colombiana. Entonces es cuando la comunidad internacional advierte que hay un peligro grave, un peligro real, y que la guerrilla colombiana es realmente una amenaza, no solamente para la estabilidad institucional de Colombia sino también para la estabilidad institucional de los demás países de la región, y que puede convertirse en un modelo perverso de exportación para otras naciones, no solamente para América Latina sino también para el mundo. Una guerrilla dejada en libre crecimiento, financiada por el narcotráfico inicialmente, que por esa misma razón adquiere gran poderío militar, y que en un determinado momento podría tomarse el poder. Es entonces cuando, por la vinculación de la guerrilla con el narcotráfico, el tema de la guerrilla colombiana comienza a ser un problema y un tema internacionales.

La guerrilla colombiana sabe también que necesita incluirse dentro del 
contexto internacional, y ha jugado un rol internacional. Ha mantenido "embajadores" en numerosos países, no solamente de Latinoamérica sino también de Europa. Las posiciones de la guerrilla colombiana frente a los demás países, y especialmente ante los países limítrofes, son variadas. La primera, de asustarlos, con el fin de crearse cierto respeto. La segunda, la de conseguir una indiferencia pasiva, especialmente en los países limítrofes, que no interfieran ante la guerrilla, que cierren los ojos ante la guerrilla. La tercera, sería la indiferencia activa, ya no sólo de no ver sino de tratar de colaborar; y la cuarta, el reconocimiento de un status de beligerancia. Básicamente esos son los cuatro puntos que la guerrilla quisiera conseguir con los países limítrofes de Colombia. Hasta ahora el status de beligerancia no se lo ha concedido ningún país. Ningún país le dará beligerancia a la guerrilla colombiana, porque darle beligerancia equivaldría a reconocerle un status político a una organización que está vinculada con el narcotráfico.

Cuando agonizaba el gobierno de Somoza, algunos países le concedieron el status de beligerancia a los sandinistas, pues estaban luchando contra una dictadura, no contra un estado democrático, y al fin y al cabo no estaban vinculados al narcotráfico para financiar su accionar en contra del régimen de Somoza. Todo lo que se haga, y esto es una apreciación mía, para ayudar a la guerrilla colombiana, en último término revierte en una ayuda al narcotráfico, y al narcotráfico internacional, y colocaría evidentemente a cualquier país en una circunstancia incómoda frente al resto de la comunidad internacional.

En ese contexto, internacionalizado el tema de la guerrilla colombiana, lo que el Presidente Pastrana ha tratado de buscar es la internacionalización de la paz. Y aquí voy a identificar un poco el proceso de paz en Colombia, porque hay ciertos malos entendidos, que es importante despejar ante la opinión internacional.

El hecho de reconocer que el conflicto colombiano tiene esa connotación, de la vinculación de la guerrilla con el narcotráfico, nos coloca en un contexto internacional. Terminado el cuatrienio anterior, cuyo presidente se vio cuestionado por haber recibido en su campaña dineros provenientes del narcotráfico, (reconocimiento que hizo la Sala Penal de la Corte Suprema de Justicia, que es cosa juzgada a la luz de la legislación colombiana), se inicia una nueva etapa para Colombia y para la institucionalidad colombiana en el campo internacional. Ya se puede hablar con los demás países y decirles que Colombia no es un país delincuente. Colombia es un país gobernado por 
gente honesta, que quiere luchar contra la corrupción, que quiere luchar contra el narcotráfico, que quiere convertirse en un estado de derecho en donde se respetan la Constitución y las leyes.

Colombia aspira a conseguir la colaboración de la comunidad internacional con tres condiciones, que han sido muy claras por parte de la Cancillería en varios comunicados. El primero, que la ayuda venga por solicitud del gobierno de Bogotá; no se trata de una ayuda espontánea en que todo el que quiera esté ayudándonos; en segundo lugar, que sea planificada y coordinada con el Gobierno de Bogotá; y en tercer lugar, que no se trate de una injerencia indebida en los asuntos internos de Colombia.

Algún participante en este Seminario preguntó por qué el grupo de Río no intervenía más en Colombia. Otro distinguido participante dijo «¿Dónde está la OEA, dónde está la ONU, dónde está el Grupo de Río, dónde están los países amigos?». Es posible que en algún momento determinado se tenga que acudir a esos mecanismos, y ello es bueno, el Gobierno colombiano lo considera como muy efectivo y muy positivo en el proceso de paz, pero todo a su debido momento. El gobierno no puede llamar unilateralmente a la ONU a decirle, «venga y sirva de visitadora», porqué entonces eso implicaría que las FARC respondan que no aceptan ahora ninguna verificación, ninguna intervención de la ONU, abandonan la mesa, cesan el dialogo. Para mucha gente que no es capaz de entender por qué se sigue dialogando en medio de la guerra, la respuesta es muy sencilla. La situación es: o guerra únicamente, o desafortunadamente guerra y también diálogo, para ver si el diálogo permite llegar al final de la guerra.

La internacionalización de la paz consiste en que Colombia recibe y solicita, por el momento, la ayuda económica de la comunidad internacional, con el objeto de asumir los inmensos costos económicos que tiene el Proceso de Paz, y que van a ser cuantiosos cuando a ella lleguemos. Y que en segundo lugary en su debido momento, solicitará, cuando también en eso haya acuerdo en la mesa de diálogo, la ayuda de la ONU, del Grupo de Río y de los otros países amigos. Todo eso porque uno lee información en donde no se entiende muy bien por qué el Presidente Pastrana creó una zona de despeje o de distensión. El Embajador Salazar ya dijo que la ley 418 lo permite. Es decir, el Presidente Pastrana ha actuado dentro de la constitución y de las leyes de Colombia. Porque, evidentemente, todo diálogo con cualquier movimiento subversivo, y así ocurrió en Guatemala y en El Salvador, implica que hay que 
darles alguna seguridad a las personas que están en la subversión, de que van a tener su integridad física a salvo. No es como algunos comentaristas dicen, que por el hecho de que el Presidente Pastrana haya conversado con la guerrilla la ha legitimado y le ha dado status de beligerancia. La ley colombiana dice que se les puede dar status político, y si el Presidente Pastrana ha conversado con la guerrilla, que tiene conexiones con el narcotráfico, es porque en Colombia se considera, y en Estados Unidos se considera, y la comunidad internacional informada considera que una de las grandes dificultades que tiene Colombia para luchar contra el narcotráfico es el hecho de que la guerri1la tenga vínculos con el narcotráfico. Si el Presidente Pastrana lograse que las guerrillas de las Fuerzas Armadas Revolucionarias de Colombia y del Ejercito de Liberación Nacional entreguen las armas y cesen en su accionar, se abriría un amplio camino para que el estado colombiano pueda luchar más efectivamente en contra del narcotráfico.

El Presidente Pastrana dialoga con una guerrilla, que si bien es cierto se financia a través de la protección que le brinda al narcotráfico, porque también conserva ella finalidades políticas. Uno de los primeros puntos de la agenda de conversaciones con las Fuerzas Armadas Revolucionarias de Colombia es la colaboración de las Fuerzas Armadas Revolucionarias de Colombia en la erradicación de cultivos ilícitos. Claro que aquí las Fuerzas Armadas Revolucionarias de Colombia entrarán en un dilema: una guerrilla que tiene 10 mil hombres, cuyos costos de mantenimiento son enormes, $-10 \mathrm{mil}$ hombres comiendo todo el día, vistiéndolos, dándoles armamento y además pagándoles un salario-, si abandona su alianza con el narcotráfico queda desfinanciada. La constante histórica de las guerrillas muestra que guerrilla que comienza a descender es guerrilla que comienza a perder. Ella, en la historia clásica de la guerra de guerrilla, está condenada a esto. Por otro lado, si no abandona su alianza con el narcotráfico, va a tener a la comunidad internacional en contra. Entonces ahí está el dilema. De todas maneras, la zona de distensión, y las conversaciones del Presidente Pastrana con las Fuerzas Armadas Revolucionarias de Colombia están orientadas a concluir la desmovilización, y por ende, a facilitarle al Estado colombiano una mejor lucha en contra del narcotráfico.

Yo quisiera complementar un poco con relación a la presentación del Sr. Mauricio Vargas, que son los mitos en relación con lo que es la guerrilla colombiana. Saliéndome del contexto internacional, voy a referirme a una serie 
de mitos que todavía se repiten y que nos han perjudicado enormemente en la lucha contra la subversión.

El primero de ellos es el mito de la pobreza. Aquí aclaro que los que están contribuyendo a desbaratar el mito de la pobreza no son los políticos, ni son los funcionarios del gobiemo, porque cuando alguien se atrevía a decir en Colombia que la pobreza no es la causante de la subversión, inmediatamente lo señalaban de fascista, clasista, oligarca, alguien que no quiere que se luche contra la pobreza.

Hay un libro, que para mí es uno de los mejores que se han publicado sobre la violencia en Colombia, que se titula: «Dos Ensayos Especulativos sobre la Violencia». Uno de ellos es del Profesor Malcolm Deas, a quien nadie puede decir que esté parcializado o ideologizado, porque el Profesor Deas es un profesor inglés, de Oxford, y no tiene ninguna vinculación con el gobierno ni con partido político alguno colombiano. El segundo ensayo especulativo es de un académico colombiano de la Universidad Nacional, Fernando Gaitan. Cuando yo leí ese libro, quise conocer al profesor Gaitan, porque me Ilamó mucho la atención el rigor científico utilizado. La tesis que ambos sostienen es que la pobreza no es la causante de la subversión. Es uno de los elementos que ayudan a la subversión. Si ustedes toman un ejemplo, en la frontera con el Ecuador, al norte, en Colombia hay muchos guerrilleros. Si pasan la frontera al sur, se darán cuenta que no hay guerrilla ecuatoriana, y las condiciones sociales y económicas son las mismas, inclusive uno podría decir que hay más pobreza en el norte de Ecuador que en el sur de Colombia. Sin embargo, hay guerrilla en el sur de Colombia y no al norte de Ecuador. Pero ese mito nos ha llevado entonces a que digan que mientras no se acabe con la pobreza habrá en Colombia guerrilla. Y es ciertamente perverso, porque una de las razones por las cuales en Colombia no se puede luchar contra la pobreza es porque tiene que destinar buena parte de su presupuesto a su seguridad, en todos los órdenes. Si nosotros esperamos a que se acabe la pobreza para hacer la paz, estaríamos condenados a estar peleando y combatiendo durante mucho tiempo.

Colombia es un país que durante 30 años ha tenido un crecimiento constante de su producto interno bruto, no obstante el conflicto. Este año, por razones que no es el caso señalar aquí, va a tener un decrecimiento. Sin embargo, estudiosos dicen que sin la guerrilla, sin la subversión, sin esos problemas, hubiese podido crecer entre un 9 y un $10 \%$ anual, lo cual obviamente hubiese ayudado a luchar en contra de la pobreza. 
Hay un ciudadano del mundo que se llama Alain Touraine, quien dirige el Instituto de Estudios Latinoamericanos en Francia, que pertenece a la izquierda, que dice que las guerrillas en el mundo han contribuido, no a la democracia, no a que haya redistribución de la riqueza, sino a que se polaricen más las opiniones, y que les han impedido a los Estados hacer políticas de bienestar social.

En segundo lugar, entre los académicos se está cuestionando el mito de que los colombianos somos violentos. Yo he oído que muchos expositores han repetido una y otra vez que los colombianos somos violentos. En el mismo libro del profesor Deas y del profesor Gaitan, se sostiene que Colombia es un país que ha tenido en oportunidades épocas de violencia. Nadie puede negar que toda Latinoamérica tuyo guerras civiles en el siglo pasado, unos países más que otros, pero esa fue una constante latinoamericana. Entre el año 1902, cuando terminó en Colombia la guerra de los mil días, y 1948, Colombia tuvo paz. Claro, hubo casos de violencia aislada, había muertes, había asesinatos, había seguramente temas de política que concluían en violencia, pero Colombia tuvo paz. Un país que durante un siglo, en la mitad de su siglo tiene paz, no puede decirse que sea un país violento. Además, afortunadamente, los investigadores científicos, sociólogos y médicos rechazan la tesis que trató de ponerse en boga, según la cual la violencia era un problema genético, de una hormona que predisponía a unos seres humanos más que otros a ser agresivos. Si eso fuera así, los colombianos deberían tomarse una pastillita diaria para ser menos violentos. La violencia es cultural y se ha agudizado en los últimos años. Este es un mito que en buena hora los investigadores y los académicos están destruyendo, porque nos condenaría a ser violentos, y a seguir sufriendo hasta el fin de los siglos este problema de la violencia.

En tercer lugar, el Profesor Manuel Domingo Rojas hace referencia al mito fundacional, y el Embajador Salazar lo repite. Perdónenme que tenga alguna discrepancia con este último. Aquí el tema de la frase: «Quien controla el pasado controla el futuro». Algún historiador dijo: «A los historiadores se les ha dado una facultad que no tiene ni Dios, y es la facultad de poder modificar el pasado», por eso tratan de manipularlo. Entonces, hay que entender que la guerrilla en Colombia no tiene el mismo origen que tuvieron casi la totalidad de los demás movimientos guerrilleros de Latinoamérica. La guerrilla en Colombia nace cuando, -y yo soy liberal y no quiero herir a ningún conservador-, el partido conservador, en el año 1948, comenzó a hostilizar al partido liberal, y el partido liberal organizó guerrillas. 
El Sr. Manuel Marulanda, conocido como «Tiro Fijo» fue guerrillero liberal. Yo no tenía uso de razón política cuando sucedía eso, pero les puedo decir que he leído mucha literatura y en mi corazón se formó el mito del guerrillero. Guadalupe Salcedo era un personaje, un guerrillero liberal que se alzó contra los gobiernos conservadores en defensa de los liberales, que firmó la paz durante el Gobierno del General Rojas y que luego lo mataron. Entonces ese mito fundacional ha hecho que, por lo menos en lo que dice relación con el partido liberal, que es hasta ahora el partido mayoritario en Colombia, la guerrilla tenga la calidad de permanecer; que el guerrillero se haya visto como un hombre idealista, que está luchando por imponer mejores condiciones de vida y exponiendo su propia vida para conseguir que se acabe con la pobreza y terminen las injusticias sociales. Los colombianos hemos querido a la guerrilla por su origen, incluso los colombianos más pacíficos, y este mito es lo que nos ha impedido luchar contra la guerrilla. Sin embargo, una guerrilla que inició la guerra, lo demuestra la historia, cuando dura demasiado tiempo, se degenera.

La guerrilla colombiana es una guerrilla que recurre al secuestro, que recurre a la extorsión. Nuestro embajador en Chile habló de las compañías petroleras que daban plata a la guerrilla, "contribución" lo llamó, de las compañías petroleras, lo que nos es "contribución" sino el fruto de la extorsión, de un delito. Yel secuestro es un delito, y matar es un delito, y así volvemos a la eterna discusión de la política entre fines y medios, que es lo que los jesuitas señalan que dijo Macquiavello. Macquiavello no lo dijo, pero sí, toda su teoría se resume en que el fin justifica los medios. Y el hecho de buscar unas condiciones sociales y económicas mejores ijustifica matar, secuestrar, extorsionar? que es justamente lo que ha hecho la guerrilla. Entonces el mito fundacional de una guerrilla buena, de una guerrilla autodefensiva, ya no nos funciona, porque la guerrilla se degeneró. $Y$ ahí es donde el proceso de paz del Presidente Pastrana tiene, a mi entender, la inmensa ganancia, que hasta ahora no se le han reconocido pero, que se la reconocerán los colombianos en su momento y se la reconocerá también la comunidad internacional. Es la primera vez que un Presidente se compromete directa y personalmente con la paz. Aniesga todo su capital político para solucionar el problema de la paz y crea una zona de distensión.

Unos meses antes de asumir la presidencia el Doctor Andrés Pastrana, el $84 \%$ de los colombianos insistían en el dialogo, por esa creencia en el guerri- 
llero bueno. «Oiganlos, lo que quieren es que haya cambios institucionales para acabar con la pobreza y con la injusticia y para tener mas democracia». El presidente Pastrana dice: «Los oigo, abro el diálogo, converso con el Sr. Manuel Marulanda". Pero ojo, la guerrilla es injusta, continua atacando, la guerrilla, por cualquier razón dice: "suspendo las conversaciones». Entonces, la opinión pública ha dado una vuelta de 180 grados. No, éstos no son los señores que quieren que los oigan, los que quieren dialogar, lo que quieren es seguir combatiendo y seguir matando. Por eso hoy día la inmensa mayoría de los colombianos ya no cree en la guerrilla.

El último mito que quiero tratar es el de la función militar. Nuestro embajador en Chile, el doctor Salazar, asegura que él no cree en la solución militar. Esa posición sí que nos ha hecho daño. Al creernos ese cuento hemos desestimado el papel que juegan las fuerzas armadas en un proceso de paz. Una guerrilla que vea unas fuerzas armadas débiles y que considere que por medio de los fusiles llegará el poder, nunca negocia. Al contrario, ciertos elementos de la sociedad, de manera equivocada y con un proceder ilegal e ilícito, pueden verse tentados a financiar grupos paramilitares al considerar que el ejército regular es débil.

Pero ese mito de que la solución no es militar, así de simplista, es grave. Acudo al símil de la enfermedad. Se va donde el médico que prescribe tres remedios y una dieta. Y si el paciente pregunta a otro facultativo si uno sólo de los medicamentos le sirve para su curación, la respuesta, a la pregunta mal formulada, será negativa.

Así en nuestro caso. La solución al problema de la guerrilla debe obedecer a una estrategia integral, que conjugue, primero que todo, el factor político; luego el social que relegitime al estado; luego el económico; luego el militar, el jurídico, el internacional y así muchos otros. Y a la afirmación de que la solución no es la militar, ha seguido la conclusión falsa de que hay que dejar a un lado este aspecto, con las muy graves consecuencias de que en Colombia, en guerra como hemos estado, hemos sido cicateros con las finanzas para las fuerzas armadas. No podemos sacar de la solución al tema militar, porque, como en el caso del enfermo, si bien lo sólo militar no nos curará de nuestra enfermedad, sí es ése un componente básico en la medicación de nuestra curación.

Para terminar, quiero afirmar algo que parecerá exagerado: en este momento la guerrilla colombiana marcha hacia su derrota. Que ha sido el desti- 
no de las guerrillas latinoamericanas, salvo cuando enfrentaron a una dictadura, como en Cuba y Nicaragua. Está derrotada por varias razones. Cito sólo tres: perdió la iniciativa militar y nada de lo programado en este campo le ha resultado en estos últimos doce meses; está aislada internacionalmente, con motivo de su vinculación con el narcotráfico; y ha perdido toda legitimidad ante los colombianos, que según encuestas serias, repudia su accionar, después de los diálogos ofrecidos por el gobiemo colombiano, que, repito, repudia en un $96 \%$ su acción y su forma de proceder. Se ha quedado sin retaguardia la subversión en Colombia y no le servirán los intentos populistas que hace para tratar de legitimarse.

Finalizo diciendo que este es el momento mejor para que la guerrilla haga la paz. Sus finanzas fuertes le permitirán hacer mucho daño y llevar a cabo escaladas militares graves, pero el quiebre de su marcha hacia su derrota se ha producido ya. Y tanto cuánto se demore en hacer la paz acordada, tanto cuánto le corresponderá hacerla en medio de una debilidad cada vez más creciente.

\section{Sumario}

La financiación de la guerrilla colombiana mediante sus nexos con el narcotráfićo coloca este conflicto en el ámbito internacional. La internacionalización de la paz por parte del presidente Pastrana y las tres condiciones de la ayuda de la comunidad de naciones. Los mitos que hay que aclarar: la pobreza como causa, el mito fundacional y la falsa apreciación sobre la solución militar. Por una estrategia integral...Porque la guerrilla colombiana marcha hacia su derrota. 